\title{
Improvements to estimating the air-sea gas transfer velocity by using dual-frequency, altimeter backscatter
}

\author{
Lonneke Goddijn-Murphy $^{\mathrm{a}, *}$, David K. Woolf ${ }^{\mathrm{b}}$, Bertrand Chapron ${ }^{\mathrm{c}}$, Pierre Queffeulou ${ }^{\mathrm{c}}$
}

\author{
${ }^{a}$ Environmental Research Institute, UHI-NHC, Thurso, Scotland, UK \\ ${ }^{b}$ International Centre for Island Technology, Heriot Watt University, Stromness, Scotland, UK \\ ${ }^{\mathrm{c}}$ IFREMER, Plouzané, France \\ *: Corresponding author : Lonneke Goddijn-Murphy, tel.: +44 1847 889664; fax: +44 1847889001 \\ email address : Lonneke.Goddijn-Murphy@uhi.ac.uk
}

\begin{abstract}
:
Air-sea gas exchange is affected by sea surface roughness and a previous study shows a significant relation between Ku-band backscattering from satellite altimeters and field estimates of gas transfer velocity, $K$. Recently C-band backscatter data were made available for altimeters on board the JASON-1 and JASON-2 satellites. In this paper we used experimental data from the same cruises to show that using the difference between the Ku-band and C-band signals to estimate sea surface roughness, and thus reducing the contribution from longer waves, improved the $K$ estimates. This is consistent with the theory that gas transfer is largely controlled by short capillary-gravity waves. For satellite data closer than $2 \mathrm{hr}$ and $0.5^{\circ}$ from the $K$ sample stations, the dual-frequency parameterization is found to perform better than a wind speed parameterization that uses in situ wind speed. The improvement supports the hypothesis that gas transfer is more directly related to surface roughness than to surface wind.
\end{abstract}

\section{Highlights}

We relate satellite altimetry signals to in situ air-sea gas transfer velocity $(K)$ For sufficiently precise collocation a dual frequency $K$-algorithm was superior - The dual frequency algorithm was superior to the in situ wind speed algorithm - The dual frequency algorithm was also superior to the single frequency algorithm

Keywords: Air-sea gas transfer ; Satellite altimetry ; DMS 


\section{Introduction}

Air-sea gas exchange has been studied for many decades because of its important role in the processes that regulate, for example, climate change, the global carbon cycle and ocean acidification. The gas transfer velocity, $K(\mathrm{~cm} / \mathrm{hr})$, is a key variable, but there is still a lot of uncertainty in its estimation. The most common $K$ parameterizations are empirical relations with $10 \mathrm{~m}$ wind speed, $U_{10}(\mathrm{~m} / \mathrm{s})$, (e.g., Liss and Merlivat, 1986; Nightingale et al., 2000; Wanninkhof, 1992; Wanninkhof and McGillis, 1999; Wanninkhof et al., 2009). These are insufficient on a global scale because other factors affect air-sea gas transfer as well, such as, surface films, wave breaking and bubbles (Nightingale, 2009; Wanninkhof et al., 2009). An example of the consequences of the wide range of "wind speed only" parameterizations is major differences in the calculation of total carbon budgets (Fangohr et al., 2008). The wind controls air-sea gas exchange through influences on the surface waves and near surface turbulence. An alternative approach is therefore to more directly link sea surface roughness represented by the mean square slope, $\left\langle s^{2}\right\rangle$, of short capillary-gravity waves to gas transfer velocity (Bock et al., 1999). Using sea surface roughness instead of wind speed was expected to improve the $K$ predictions. For satellite altimeters operating at nadir view radar backscatter, $\sigma$, is closely inversely proportional to $\left\langle s^{2}\right\rangle$ (Brown, 1979). As demonstrated by Vandemark et al. (1997), altimeter $\sigma$ measurements are closely related to surface wind stress for light to moderate winds. Moreover, it is known that using dual-frequency altimeter data provides measurements more directly linked to short-scale surface roughness (Chapron et al., 1995; Elfouhaily et al., 1998). The contribution of longer waves is attenuated by using dual-frequency altimeters, and differencing the C-band signal, $\sigma_{\mathrm{C}}(5.3 \mathrm{GHz}, 5.5 \mathrm{~cm}, 40$ $\mathrm{rad} / \mathrm{m})$, and Ku-band signal, $\sigma_{\mathrm{Ku}}(13.6 \mathrm{GHz}, 2.1 \mathrm{~cm}, 100 \mathrm{rad} / \mathrm{m})$, for more reliable gas transfer velocity estimates (Frew et al., 2004, 2007; Glover et al., 2002, 2007). However, the contribution of longer waves, i.e. the presence of swell, cannot be fully removed by differencing the two band signals. Although the long-wave tilt effects have been demonstrated to linearly act on nadir signals (Vandemark et al., 2004), short gravity-capillary waves do not affect uniformly the altimeter-effective Fresnel coefficients for Ku and $\mathrm{C}$ bands (e.g., Elfouhaily et al., 1998). In contradiction to the expectation described above, gas transfer velocity has also been found to correlate slightly better with total $\left\langle s^{2}\right\rangle$, than with the $\left\langle s^{2}\right\rangle$ of short wind waves only, in the absence of large scale wave breaking (Bock et al., 1999; Jähne et al., 1987). This improved correlation to total slope is difficult to explain since the longer waves are not directly involved in the air-sea exchange process. Fangohr and Woolf (2007) and Goddijn-Murphy et al. (2012) have successfully used single Ku-band backscattering, $\sigma_{\mathrm{Ku}}$, to estimate gas transfer velocity.

The current study builds on a previous study by Goddijn-Murphy et al. (2012), but presents further analysis using recently added C-band data from the same altimeter database. The analysis of Goddijn-Murphy et al. (2012) shows that field measurements of $K_{w, 660}$ (gas transfer velocities corrected to a Schmidt number of 660) depend on the inverse of satellite altimeter observed $\sigma_{\mathrm{Ku}}$. That study used $K_{\mathrm{w}, 660}$ obtained using the eddy-correlation (EC) technique during eight cruises in different parts of the world and during different times of the year. The cruises PHASE1 (Marandino et al., 2007), Knorr_06 (Marandino et al., 2009) and Knorr_07 (Marandino et al., 2008) were performed by the University of California, Irvine, (UCI), while the University of Hawaii (UH) carried out the cruises TAO (Huebert et al., 2004), BIO (Blomquist et al., 2006), DOGEE (Huebert et al., 2010), SO-GasEx (Yang et al., 2011) and VOCALS-Rex (Yang et al., 2009). The measured gas was dimethyl sulfide (DMS). Because DMS is a moderately soluble gas, bubble-mediated gas transfer can be neglected (Woolf, 1993, 1997) and the DMS measurements can be used to model water-side gas transfer velocities, $k_{\mathrm{w}, 660}$, through the unbroken surface of any other gas (Goddijn-Murphy et al., 2012). 
Studies of the type presented here depend on high-quality satellite data. Our new study in common with Goddijn-Murphy et al. (2012) depends on the calibrated and homogeneous altimeter data made available online by the French Research Institute for Exploitation of the Sea, IFREMER, at ftp://ftp.ifremer.fr/ifremer/cersat/products/swath/altimeters/waves. This data base, released in 2010, contains 20 years of data from altimeters on board satellites ERS-1, ERS-2, TOPEX/POSEIDON, GEOSAT Follow-On, JASON-1, JASON-2 and ENVISAT. All satellites carry Ku-band altimeters. For the different altimeters different calibrations and algorithms have been applied. In addition, electronic drifts and sensor degradations can induce discrepancies between the various satellites in the long-term. Queffeulou and collaborators (Abdalla, 2007; Queffeulou, 2004; Queffeulou et al., 2010) have produced a homogeneous and calibrated data set using a method based on buoy and cross-satellite comparisons. A direct comparison between $1 / \sigma_{\mathrm{Ku}}$ (where $\sigma_{\mathrm{Ku}}$ is in linear units) and $K_{\mathrm{w}, 660}$ reveals that the data best fit a quadratic equation and that the relation of $K_{\mathrm{w}, 660}$ with $U_{10}$ is practically linear, with fairly similar errors for altimeter or shipboard $U_{10}$ (GoddijnMurphy et al., 2012). Using $\sigma_{\mathrm{Ku}}$ instead of altimeter $U_{10}$ does not achieve a more accurate algorithm for $K_{\mathrm{w}, 660}$. In April $2012 \mathrm{C}$-band backscatter values, $\sigma_{\mathrm{C}}$, from JASON-1 and JASON2 were added to the data set. The focus of our new study is to investigate if $K_{w, 660}$ prediction is improved by applying two-band, instead of single-band, altimetry by using the same cruise data as Goddijn-Murphy et al. (2012) and testing the different parameterizations. This study is not the first to use Ku and C-band altimetry in air-sea gas transfer velocity studies (Frew et al., 2004, 2007; Glover et al., 2002, 2007), but it has never been directly linked to gas transfer velocities measured at sea before. We report a significant improvement by using a two-band algorithm, but note some caution given the limited number of collocated data.

\section{Gas transfer velocity parameterizations}

Fangohr and Woolf (2007) apply the linear relation,

$$
K_{w, 660}=C+\frac{A}{\sigma_{K u}}
$$

to TOPEX altimeter $1 / \sigma_{\mathrm{Ku}}$, while Goddijn-Murphy et al. (2012) find a non-linear relation

$$
K_{w, 660}=C+\frac{A}{\sigma_{K u}^{2}}
$$

to be a better fit. Glover et al. (2002) propose to remove the contribution of longer waves by differencing the signals of the Ku- and C-bands of the TOPEX altimeter before employing a linear relation,

$$
K_{w, 660}=C+A\left(\frac{1}{\sigma_{K u}}-\frac{B}{\sigma_{C}}\right)
$$


Frew et al. (2004) use field measurements of heat transfer extrapolated to gas transfer velocities at sea and find that $K$ varies linearly with $\left\langle s^{2}\right\rangle$ for wavenumbers between 40 and $800 \mathrm{rad} / \mathrm{m}$ while for wavenumbers between 40 and $100 \mathrm{rad} / \mathrm{m}$ the data is best fitted by a quadratic relation. These findings imply that for the $\mathrm{Ku}$ band a relation of the form (1) is expected, and for the difference between the $\mathrm{Ku}$ and $\mathrm{C}$-band signals a relation of the form

$$
K_{w, 660}=C+A\left(\frac{1}{\sigma_{K u}}-\frac{B}{\sigma_{C}}\right)^{2}
$$

Glover et al. (2007) and Frew et al. (2007) apply (4) to backscatter data of the dual-frequency TOPEX and JASON-1 altimeters. A small correction term $\alpha$ can be added to $\sigma_{\mathrm{C}}$ to correct for a shift between the non-calibrated C-band and Ku-band (Chapron et al. 1995; Frew et al., 2004, 2007; Glover et al., 2002, 2007).

We also tested wind speed parameterizations with in situ and altimeter $U_{10}$. The altimeter $U_{10}$ estimates used in this study are based on calibration of sigma Ku only. Two parameter $\left(H_{\mathrm{s}}\right.$ and $\sigma_{\mathrm{Ku}}$, where $H_{\mathrm{s}}$ is the altimeter measurement of significant wave height) estimates of wind speed have also been proposed (Gourrion et al., 2002), on the principle that sea state contamination of wind speeds can be reduced; however no such estimate has been tested in this study. Common $U_{10}$ parameterizations for carbon dioxide are non-linear, but for the more soluble gas DMS the relation is practically linear

$$
K_{w, 660}=C+A U_{10}
$$

(Goddijn-Murphy et al., 2012).

\section{Methodology}

For a detailed description of the field cruises including measurement techniques of $K_{\mathrm{w}, 660}$ and $U_{10}$ we refer the reader to Goddijn-Murphy et al. (2012). Also, a description of how intercalibrated altimeter $\sigma_{\mathrm{Ku}}$ and corrected altimeter $U_{10}$ (the parameters we used in this paper) were derived by IFREMER can be found there. The IFREMER altimeter data are publicly available online at ftp://ftp.ifremer.fr/ifremer/cersat/products/swath/altimeters/waves; we used the update of April 2012 (version wave_merge_9.0). Usually $\sigma$ values are presented in a logarithmic unit $(\mathrm{dB})$ but the theoretical relationship between nadir backscatter and mean square slope is more conveniently written in non-logarithmic units (Brown, 1979). Therefore, a transformation $\sigma=10^{\sigma(\mathrm{dB}) / 10}$ is applied throughout this study. We ignored the correction term $\alpha$ (see penultimate paragraph of Section 2 ), so our regression results are necessarily specific for our altimeter data set. Matching criteria of time difference $d t<6 \mathrm{hr}$ and distance $d x<0.5^{\circ}$ between cruise station and satellite overpass are appropriate (Goddijn-Murphy et al., 2012). For all satellites, 179 such matches are found, while JASON-1 and JASON-2 combined gave 62 matches (the matches referred to in this paper). We repeated the latter search for $d t<5$, $4,3,2$ and $1 \mathrm{hr}$ while keeping $d x<0.5^{\circ}$. These data contained C-band backscattering coefficients, $\sigma_{\mathrm{C}}$, but unlike for $\sigma_{\mathrm{Ku}}$ their values were not inter-calibrated. In the IFREMER database the Jason-1/2 values of $\sigma_{\mathrm{C}}$ and of $\sigma_{\mathrm{Ku}}$ before inter-calibration are the Geophysical Data Records (GDR) provided by the AVISO-CNES data centre 
(http://www.aviso.oceanobs.com/en/data/data-access-services/aviso-cnes-data-center.html). In this version of the data, the Jason-1 data processed with the MLE-3 retracker have all been reprocessed using the MLE-4 retracker, while Jason-2 processing used the MLE-4 retracker from the start. We fitted the data of the match-ups to the proposed $K_{w, 660}$ relationships (1) - (5). Analysis of the residuals, including tests of normality and homoscedasticity, showed that the assumptions of ordinary least squares regression applied.

Gas transfer velocity parameterizations were also compared using a "bootstrap" method, in order to provide information on the statistical robustness of differences in performance. This method creates synthetic sets of data by random resampling from the original data with replacement and then analysing a large number of synthetic datasets identically to the actual dataset. Wilmott et al. (1985) describe how the bootstrap technique can be used to determine confidence and significance of geophysical models. They consider the difference of error measures between observed and predicted variables, especially the root-mean square error (RMSE), to be the paramount measure of accuracy. We applied Matlab"s "bootstrp" to create 1000 bootstrap samples of one dataset. Following Wilmott et al. (1985) we interpreted histograms of the bootstrapped RMSE values. Wilmott et al. (1985) explain that the difference between two model accuracies can be examined by evaluating the probability, $P$, that the RMSE of the fit of model 1 is larger than the RMSE of the fit of model 2. Using the bootstrapped samples, $P$ can be estimated by

$$
P\left(R M S E_{1}>R M S E_{2}\right)=1-\alpha_{0} \approx \#\left[\left(R M S E_{1}-R M S E_{2}\right)_{k}^{*}>0\right] B^{-1}
$$

(Wilmott et al., 1985), where $a_{0}$ is the observed probability level, $\left(\mathrm{RMSE}_{1}-\mathrm{RMSE}_{2}\right)_{\mathrm{k}}{ }^{*}$ the $k$ th bootstrap measure of the RMSE difference, \# the number of bootstrap samples that meet the condition, and $B$ the total number of bootstraps ( $B=1000$ in our application).

\section{Results and Discussion}

Coinciding JASON-1/2 altimeter data were found for the cruises PHASE1, Knorr_07, BIO, SO-GasEx, and VOCALS-Rex, only one for DOGEE and none for TAO and Knorr_06. The regression results of (1)-(5) are presented in Table 1 and Fig. 1. For $d t<6 \mathrm{hr}$ the inferred coefficients of (1), (2) and (5) were similar to when all satellites were considered (GoddijnMurphy et al., 2012), but the spread in the data was considerably less (smaller RMSE and higher $R^{2}$ ). This could be attributed to differences between the satellites, despite the intercalibration, and between the cruises as less cruises coincided with the JASON-1 and -2 over passes and the cruise-specific regressions vary considerably (Goddijn-Murphy et al., 2012). In agreement with the previous findings, single Ku band data fitted a quadratic relation (2) more closely than a linear relation (1). Using the two bands $\mathrm{Ku}$ and $\mathrm{C}$, however, a linear relation of the scattering difference (3) appeared to be a better fit than a quadratic relation (4) and also better than the relation with altimeter wind speed (5). Over the whole $d t$ range, the linear two-band (3) performed best of the altimeter algorithms. For $d t \leq 2 \mathrm{hr}$, (3) appeared to be even better than the algorithm based on in situ wind speed (5).

We applied the bootstrap technique to compare the best single-band, the best dual-band and the in situ wind speed parameterizations using the the $d t<1 \mathrm{hr}$ and $d t<2 \mathrm{hr}$ datasets. Including other less successful parameterizations would largely confuse the issue. The 
distributions of RMSE, illustrated in Fig. 2, were centred on a lower value using (3) than using in situ wind speed predictions (5) and also than using (2). The 95\% confidence limits showed some overlap (Table 2), however. Using (6) we inferred that the probability that the RMSE using in situ wind speed (5) was bigger than using two bands (3) was $0.92(0.89)$ for $d t<2 \mathrm{hr}(1 \mathrm{hr})$. The RMSE for single band algorithm (2) is also bigger than (3) but with less confidence, the probability being $0.88(0.78)$ for $d t<2 \mathrm{hr}(1 \mathrm{hr})$.

As would be expected, the $K_{w, 660}$ estimations using altimeter-derived parameters improved with decreasing temporal separation while the one using shipboard $U_{10}$ stayed more or less the same with exception of a marked decrease in RMSE at $d t<1$ (Fig.1). The latter could be explained by the absence of SO-GasEx data in the $d t<1$ match-ups (Fig. 3top). According to Yang et al. (2011) SO-GasEx is different from the other UH cruises by more frequent occurrences of stable boundary layer conditions. They explain that stable boundary layer conditions give greater uncertainty in $K_{w, 660}$ because static stability in the boundary layer increases uncertainty in the flux measurement (Blomquist et al., 2010). Also, higher winds were present during SO-GasEx implying higher variation in the wind speed and hence in $K_{w, 660}$. A greater uncertainty was confirmed by a comparison of the fits of (5) with in situ $U_{10}$ for $d t<6$ over the different cruises; for SO-GasEx the RMSE was $3.7 \mathrm{~cm} / \mathrm{hr}$, while for the other cruises the RMSE was typically $2 \mathrm{~cm} / \mathrm{hr}$. Fig. 3bottom shows that the in situ $U_{10}$ range was quite evenly distributed over the $d t$ intervals. The figure demonstrates that low wind speeds were not over-represented in the smaller $d t$ data sets, so that a decrease in RMSE for closer matches (Fig. 1) could not be attributed to relatively lower wind speeds during those matches.

\section{Conclusion}

Field estimates of gas transfer velocity were analysed with coinciding Ku-band and C-band backscattering values from satellite altimeters. Statistical tests implied that using Ku-band and C-band backscatter data gave improved $K_{\mathrm{w}, 660}$ estimations compared to using Ku-band alone. That interpretation must be made with caution, because the size of the data set is small and the results of bootstrapping tests are not wholly conclusive. However, the improvement is also supported by knowledge of the physics of air-sea gas transfer and radar altimetry. A linear empirical relation between the differences of the signals of the Ku- and Cbands (3) described $K_{\mathrm{w}, 660}$ predictions best. For small separation errors between field stations and satellite passes (distances less than $0.5^{\circ}$ and time differences under $2 \mathrm{hr}$ ), we can conclude with reasonable confidence that using the dual-frequency altimeter data (3) is superior to using in situ $U_{10}(5)$, reinforcing the theory that gas transfer is more directly controlled by sea surface roughness than by wind. The result for a time difference of under 2 $\mathrm{hr}$ was based on a total of 29 collocations from six geographically diverse research cruises. Based on the available statistics, the superiority of dual frequency algorithms appeared to be fairly robust, but more and better quality transfer velocity data should be sought for verification.

\section{Acknowledgements}

This research is a contribution of the National Centre for Earth Observation, a NERC Collaborative Centre and was supported by the European Space Agency (ESA) Support to Science Element (STSE) project OceanFlux Greenhouse Gases (contract number: 4000104762/11/I-AM). We appreciate the use of DMS concentration and flux data from the 
Huebert group at the University of Hawaii and also from the Saltzman group at the University of California, Irvine, made available by Christa Marandino.

\section{References}

Abdalla, S. (2007), Ku-band radar altimeter surface wind speed algorithm, paper presented at ENVISAT Symposium 2007, Eur. Space Agency, Montreux, Switzerland, 23-27 April.

Blomquist, B. W., C. W. Fairall, B. J. Huebert, J. W. Kieber, and G. R. Westby (2006), DMS sea-air transfer velocity: Direct measurements by eddy covariance and parameterization based on the NOAA/COARE gas transfer model, Geophys. Res. Lett., 33(L07601)

Blomquist, B. W., B. J. Huebert, C. W. Fairall, and I. C. Faloona (2010), Determining the sea-air flux of dimethylsulfide by eddy correlation using mass spectrometry, Atmos. Meas. Tech., 3, 1-20, doi:10.5194/amt-3-1-2010.

Bock, E. J., T. Hara, N. M. Frew, and W. R. McGillis (1999), Relationship between air-sea gas transfer and short wind waves, J. Geophys. Res., 104(C11), 25,821-25,831.

Brown, G. S. (1979), Estimation of surface wind speeds using satellite-borne radar measurements at normal incidence, J. Geophys. Res., 84(B8), 3974-3978.

Chapron, B., K. Katsaros, T. Elfouhaily, and D. Vandemark (1995) A note on relationships between sea surface roughness and altimeter backscatter, In: Air-Water Gas Transfer, Selected Papers from the Third International Symposium on Air-Water Gas Transfer July 2427, 1995, Heidelberg University, B. Jähne and E.C. Monahan (eds.), AEON Verlag and Studio, Hanau, pp 869-878.

Elfouhaily, T., D. Vandemark, J. Gourrion and B. Chapron, (1998) Estimation of wind stress using dual-frequency TOPEX data. J. Geophys. Res., 103(C11), 25101-25108.

Fangohr, S. and D. K. Woolf (2007), Application of new parameterization of gas transfer velocity and their impact on regional and global marine $\mathrm{CO}_{2}$ budgets, J. Mar. Syst., 66, 195203.

Fangohr, S., D. K. Woolf, C. D. Jeffery, and I. S. Robinson (2008), Calculating long-term global air-sea flux of carbon dioxide using scatterometer, passive microwave and model reanalysis wind data, J. Geophys. Res., 113(C09032).

Frew, N. M. et al. (2004), Air-sea gas transfer: Its dependence on wind stress, small-scale roughness, and surface films, J. Geophys. Res., 109(C08S17).

Frew, N. M., D. M. Glover, E. J. Bock, and S. J. McCue (2007), A new approach to global airsea gas transfer velocity fields using dual-frequency altimeter backscatter, J. Geophys. Res., 112(C11003).

Glover, D. M., N. M. Frew, and S. J. McCue (2007), Air-sea gas transfer velocity estimates from the Jason-1 and TOPEX altimeters: prospects for a long-term global time series, J. Mar. Syst., 66, 173-181.

Glover, D. M., N. M. Frew, S. J. McCue, and E. J. Bock (2002), A multi-year time series of global gas transfer velocity from the TOPEX dual frequency, normalized backscatter 
algorithm, in Gas Transfer at Water Surfaces, Geophysical Monograph, vol. 127 edn., edited by M. Donelan, W. M. Drennan, E. Saltzman, and R. Wanninkhof, pp. 325-331, American Geophysical Union, Washington, DC.

Goddijn-Murphy, L. M., D. K. Woolf, and C. A. Marandino (2012), Space-based retrievals of air-sea gas transfer velocities using altimeters; calibration for dimethyl sulfide, J. Geophys. Res., 117(C08028).

Gourrion, J., D. Vandemark, S. Bailey, B. Chapron, G. P. Gommenginger, P. G. Challenor, M. A. Srokosz, (2002), A two-parameter wind speed algorithm for Ku-band altimeters. J. Atmos. Oceanic Technol., 19, 2030-2048.

Huebert, B. J., B. W. Blomquist, M. X. Yang, S. D. Archer, P. D. Nightingale, M. J. Yelland, J. Stephens, R. W. Pascal, and B. I. Moate (2010), Linearty of DMS transfer coefficient with both friction velocity and wind speed in the modereate wind speed range, Geophys. Res. Lett., 37(L01605).

Huebert, B. J., B. W. Blomquist, J. E. Hare, C. W. Fairall, J. E. Johnson, and T. S. Bates (2004), Measurement of the air-sea DMS flux and transfer velocity using eddy correlation, Geophys. Res. Lett., 31(L01605).

Jähne, B., K. O. Münnich, R. Bösinger, A. Dutzi, W. Huber, and P. Libner (1987), On the parameters influencing air-water gas exchange, J. Geophys. Res., 92, 1937-1949.

Liss, P. S. and L. Merlivat (1986), Air-sea gas exchange rates: Introduction and synthesis, in The Role of Air-Sea Exchange in Geochemical Cycling, edited by P. Buat-Menard, pp. 113127, D Reidel, Dordrect.

Marandino, C. A., W. J. De Bruyn, S. D. Miller, and E. S. Saltzman (2008), DMS air/sea flux and gas transfer coefficents from the North Atlantic summertime coccolithophore bloom, Geophys. Res. Lett., 35(L23812).

Marandino, C. A., W. J. De Bruyn, S. D. Miller, and E. S. Saltzman (2009), Open ocean DMS air/sea fluxes over the eastern South Pacific Ocean, Atmos. Chem. Phys., 9, 345-356.

Marandino, C., W. de Bruyn, S. Miller, and E. S. Saltzman (2007), Eddy correlation measurements of the air/sea flux of dimethylsulfide over the North Pacific Ocean, J. Geophys. Res., 112(D03301).

Nightingale, P. D. (2009), Air-sea gas exchange, in Surface Ocean-Lower Atmosphere Processes, vol. 187, edited by C. Le Quéré and E. S. Saltzman, pp. 69-97, AGU, Washington, D. C.

Nightingale, P. D., G. Malin, C. S. Law, A. J. Watson, and P. S. Liss (2000), In situ evaluation of air-sea gas exchange parameterizations using novel conservative and volatile tracers, Global Biochem. Cy., 14, 373-387.

Queffeulou, P. (2004), Long-term validation of wave height measurements from altimeters, Mar. Geod., 27(3-4), 495-510, doi:10.1080/ 01490410490883478.

Queffeulou, P., A. Bentamy, and D. Croizé-Fillon (2010), Analysis of seasonal wave height anomalies from satellite data over the global oceans, paper presented at ESA Living Planet Symposium, Eur. Space Agency, Bergen, Norway, 28 June to 2 July. 
Vandemark, D., B. Chapron, J. Sun, G. H. Crescenti, and H. C. Graber (2004), Ocean wave slope observations using radar backscatter and laser altimeters, J. Phys. Oceanogr., 34, 2825-2842

Vandemark, D., J. B. Edson, B. Chapron (1997) Altimeter estimation of sea surface wind stress for light to moderate winds. J. Atmos. Oceanic Technol., 14, 716-722.

Wanninkhof, R. (1992), Relationship between wind speed and gas excahnge over the ocean, J. Geophys. Res., 97(C5), 7373-7382.

Wanninkhof, R., W. E. Asher, D. T. Ho, C. Sweeney, and W. R. McGillis (2009), Advantages in quantifying air-sea gas exchange and environmental forcing, Annu. Rev. Mar. Sci., 1, 213244.

Wanninkhof, R. and W. R. McGillis (1999), A cubic relationship between air-sea $\mathrm{CO}_{2}$ exchange and wind speed, Geophys. Res. Lett., 26(13), 1889-1892.

Wilmott, C. J., S. G. Ackleson, R. E. Davis, J. J. Feddema, K. M. Klink, D. R. Legates, J. O'Donnell, and C. Rowe (1985), Statistics for the evaluation and comparison of models, J. Geophys. Res., 90(C5), 8995-9005

Woolf, D. K. (1993), Bubbles and the air-sea transfer velocity of gases, Atmos. Ocean, 31(4), 517-540.

Woolf, D. (1997), Bubbles and their role in air-sea gas exchange, in The Sea Surface and Global Change, edited by P. S. Liss and R. A. Duce, pp. 173-205.

Yang, M. X., B. W. Blomquist, C. W. Fairall, S. Archer, and B. J. Huebert (2011), Air-sea exchange of dimethylsulfide in the Southern Ocean: Measurements from SO GasEx compared to temperate and tropical regions, J. Geophys. Res., 116(C00F05).

Yang, M. X., B. W. Blomquist, and B. J. Huebert (2009), Constraining the concentration of the hydroxyl radical in a stratocumulus topped marine boundary layer from sea-to-air eddy covariance flux measurements of dimethylsulfide, Atmos. Chem. Phys., 9, 9225-9236. 
Table 1. Regression results for the cruise data coinciding with JASON-1 and JASON-2 over passes within $0.5^{\circ}$ distance and $\mathrm{dt}(\mathrm{hr})$ time difference, using single Ku-band backscattering with (1) $A=A^{\prime \prime} \cdot 10^{2}$ and (2) $A=A " \cdot 10^{3}$; Ku-band and C-band scattering with (3) $A=A " \cdot 10^{2}$ and (4) $A=A " 10^{3}$; and in situ and altimeter wind speed with (5). The RMSE and $R^{2}$ values are shown in Fig. 1.

(1)

(2)

(3)

(4)

(5) $U_{10, \text { is }}$

(5) $U_{10, \mathrm{a}}$

\begin{tabular}{cccccccccccccccc}
$d t$ & $\#$ & $A^{\prime}$ & $C$ & $A^{\prime}$ & $C$ & $A^{\prime}$ & $B$ & $C$ & $A_{\#}$ & $B$ & $C$ & $A$ & $C$ & $A$ & $C$ \\
\hline 1 & 16 & 1.7 & -3.1 & 1.5 & 0.81 & 5.8 & 2.1 & -0.7 & 6.7 & 1.6 & 1.8 & 1.6 & -1.0 & 1.5 & -1.1 \\
2 & 29 & 2.1 & -4.7 & 1.6 & 1.05 & 6.7 & 2.2 & -0.1 & 4.2 & 1.3 & 2.2 & 1.9 & -2.1 & 1.7 & -1.6 \\
3 & 41 & 2.2 & -5.2 & 1.6 & 1.27 & 6.4 & 2.1 & -0.6 & 3.9 & 1.1 & 0.1 & 1.9 & -2.2 & 1.7 & -1.3 \\
4 & 48 & 2.2 & -5.6 & 1.6 & 1.10 & 6.4 & 2.1 & -1.1 & 3.6 & 1.0 & 2.1 & 2.0 & -2.9 & 1.7 & -1.5 \\
5 & 56 & 2.4 & -6.7 & 1.7 & 0.70 & 6.4 & 2.1 & -1.3 & 3.5 & 1.0 & 1.9 & 2.1 & -3.6 & 1.8 & -2.2 \\
6 & 62 & 2.4 & -7.0 & 1.7 & 0.61 & 6.1 & 2.0 & -2.0 & 3.0 & 0.8 & 1.6 & 2.2 & -4.0 & 1.8 & -2.3
\end{tabular}

Table 2. Bootstrap measures of RMSE (cm/hr) for the Kw,660 predictions (2), (3) and (5) with $U_{10 \text {,is. }}$.

\begin{tabular}{|c|c|c|c|c|c|c|}
\hline \multirow[b]{2}{*}{ quation } & \multicolumn{3}{|c|}{$\begin{array}{l}d t=2 \mathrm{hr} \\
\text { Confidence } \\
\text { Limits (95\%) }\end{array}$} & \multicolumn{3}{|c|}{$\begin{array}{l}d t=1 \mathrm{hr} \\
\text { Confidence } \\
\text { Limits (95\%) }\end{array}$} \\
\hline & RMSE & Lower & Upper & MSE & Lower & Upper \\
\hline 2 & & & & & & \\
\hline 3 & & 1.7 & 2. & & $1 .($ & 2. \\
\hline 5 & 3.10 & 2.16 & 3.86 & 2.29 & 1.53 & 3.03 \\
\hline
\end{tabular}




\section{Figures}

Figure 1. (top) RMSE (cm/hr) and (bottom) $R^{2}$ values for the fits of the data to equations (1) to (5), with in situ / altimeter derived $10 \mathrm{~m}$ wind speed $U_{10 \text { is }} / U_{10 . a}$, presented in Table 1; the coinciding altimeter data were within $0.5^{\circ}$ distance and dt time difference of $\mathrm{K}_{\mathrm{w}, 660}$ sample stations.
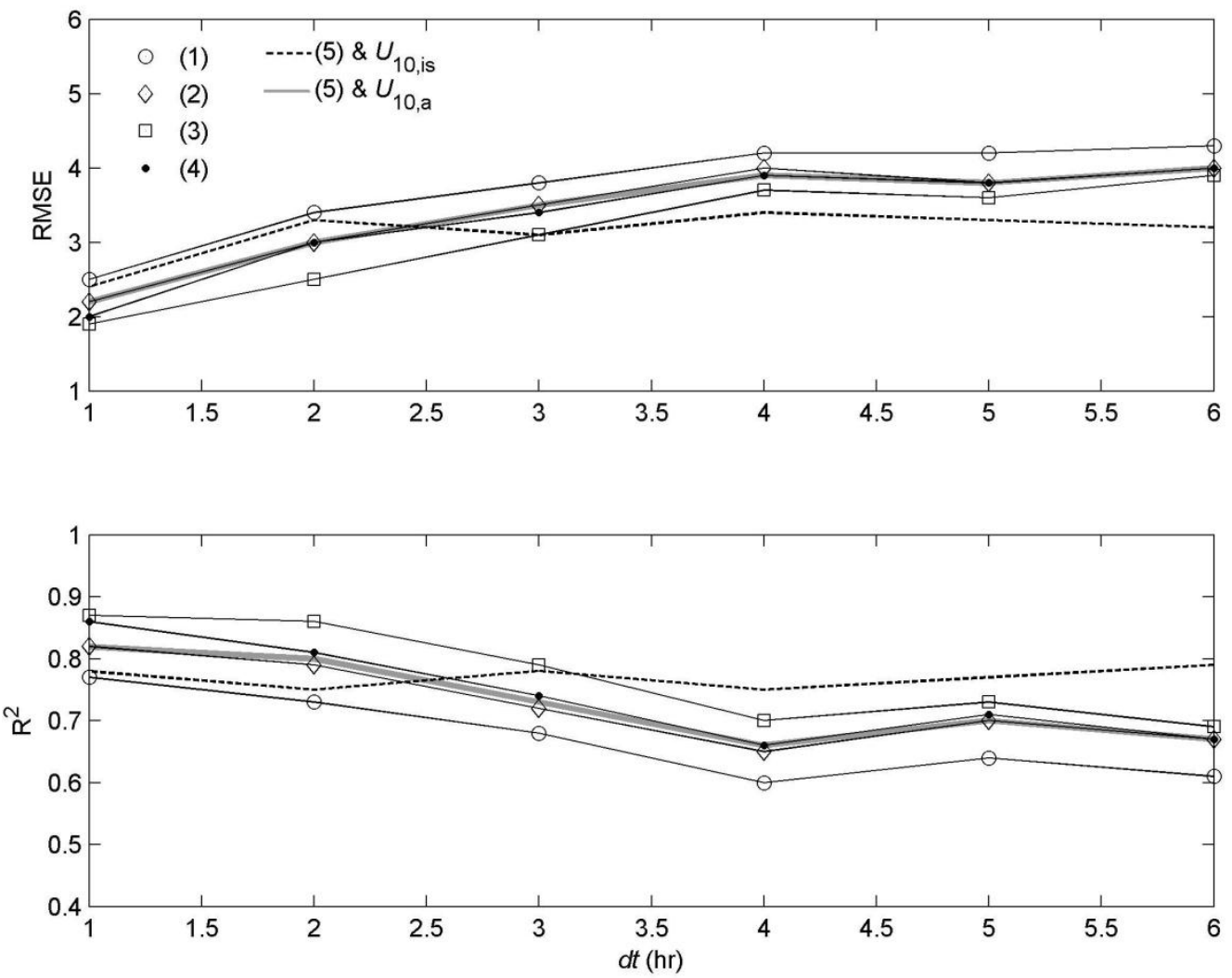
Figure 2. Bootstrapped histograms of the RMSE (cm/hr) values for the fits of the data to (2), (3) and (5) with in situ $U_{10}$; as shown in Fig. 1, but from 1000 bootstrap samples for the data sets (top) $\mathrm{dt} \leq 1 \mathrm{hr}$, and (bottom) $\mathrm{dt} \leq 2 \mathrm{hr}$.
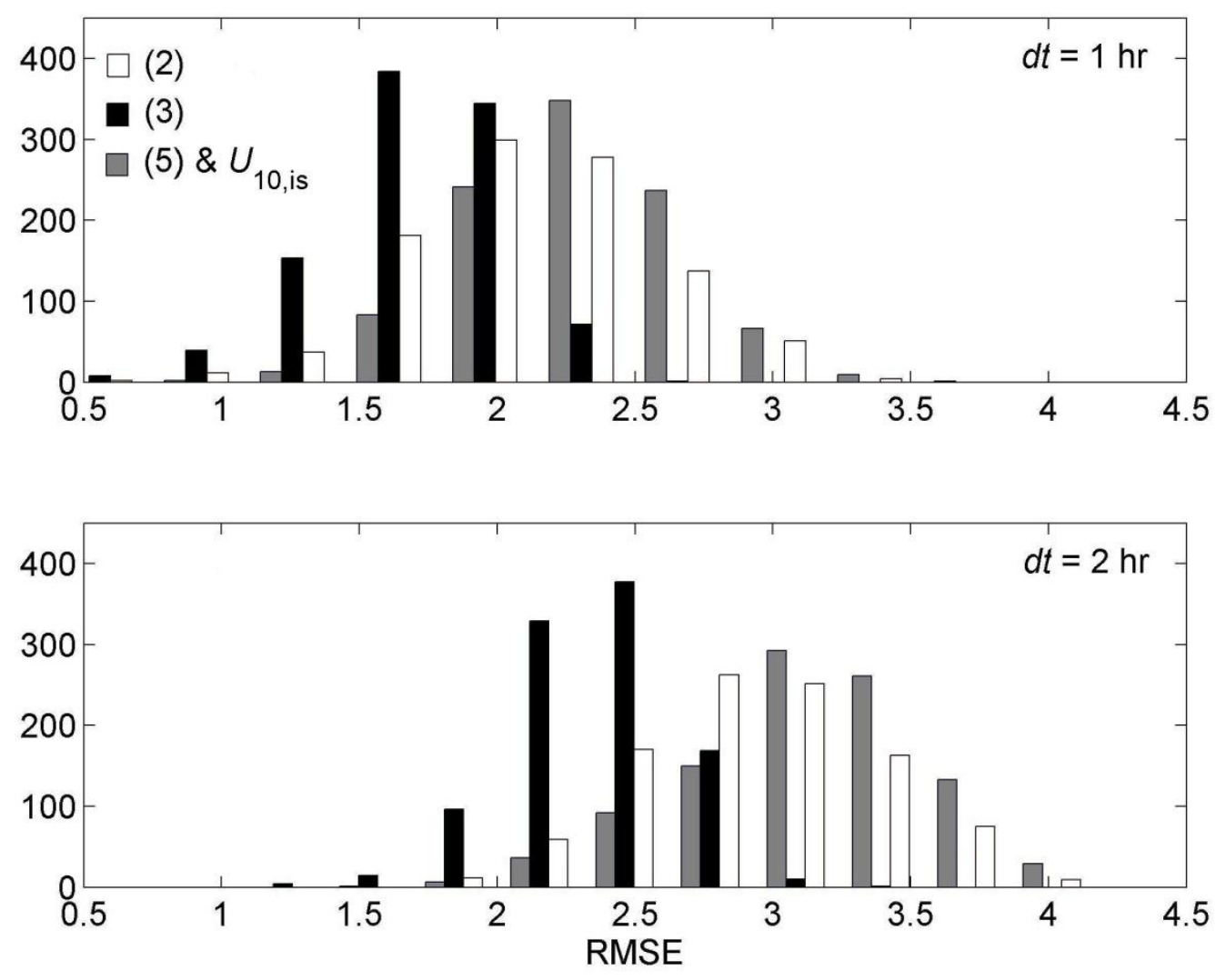
Figure 3. Frequencies of the coinciding data classified by (top) cruise per maximum time difference, $\mathrm{dt}(\mathrm{hr})$, and (bottom) dt per in situ $\mathrm{U}_{10}$ interval.
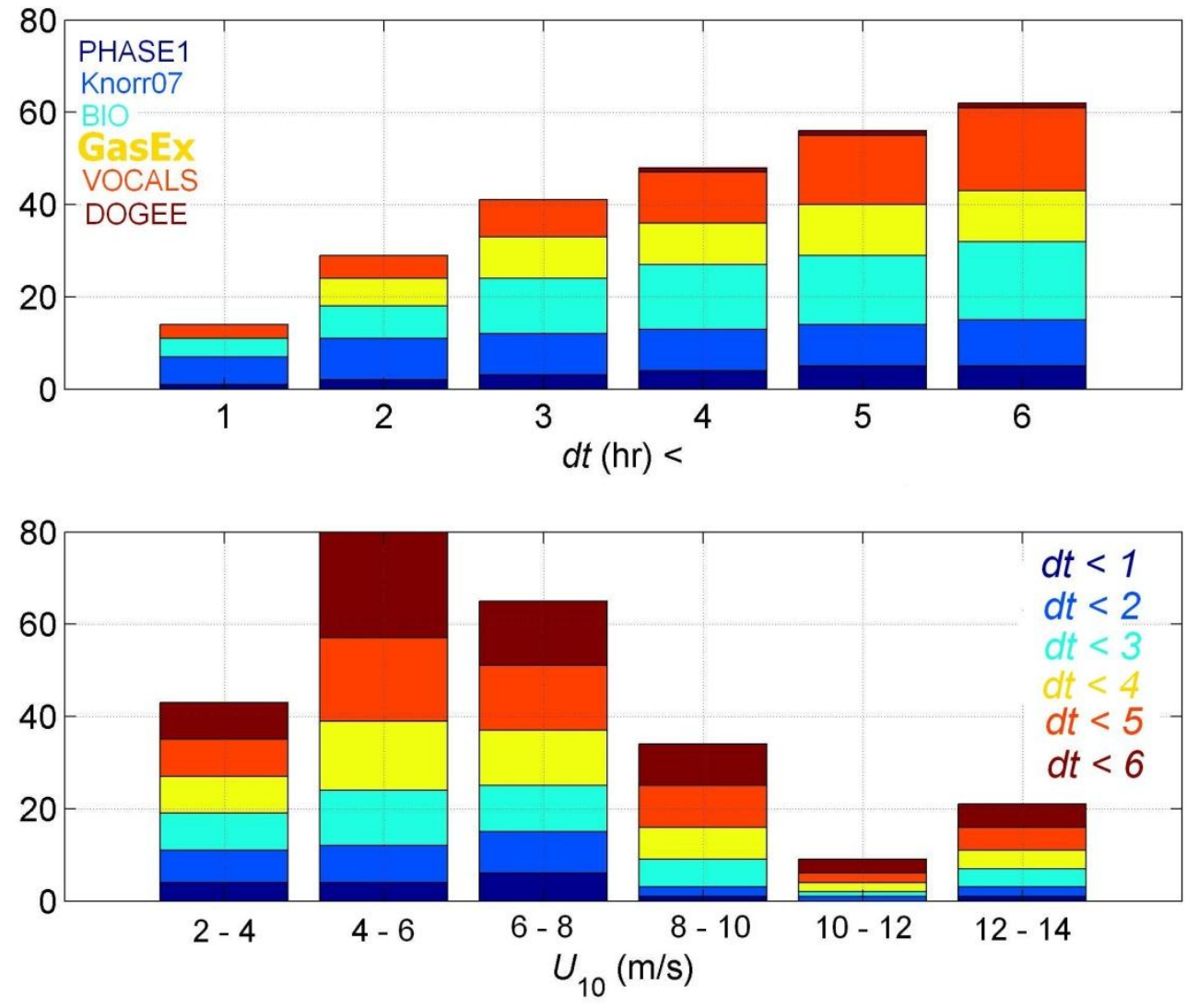